\title{
"SER TRATADA COMO GENTE":A VIVÊNCIA DE MULHERES ATENDIDAS NO SERVIÇO DE PRÉ-NATAL DE UMA INSTITUIÇÃO FILANTRÓPICA*
}

\author{
"BE TREATED A HUMAN BEING": WOMEN'S EXPERIENCE OF CARE IN A \\ PRENATAL SERVICE OF A PHILANTHROPIC INSTITUTION.
}

Isabel Cristina Bonadio**

BONADIO, I.C. "Ser tratada como gente": a vivência de mulheres atendidas no serviço de pré-natal de uma instituição filantrópica. Rev.Esc.Enf.USP. v.32, n.1, p. 9.15, abr. 1998.

\begin{abstract}
RESUMO
Este estudo, de abordagem qualitativa, tem como referencial teórico a antropologia cultural e utiliza o método etnográfico de pesquisa. Teve por objetivo conhecer e compreender as necessidades, crenças e valores do cuidado prénatal na visão e experiência vivenciada por mulheres grávidas atendidas no contexto do Serviço de Pré-Natal de uma Instituição filantrópica. A análise dos temas culturais identificados levou ao tema central "ser tratada como gente", revelando que, na vivência das mulheres, o elemento mais significativo é representado pela interação efetiva ou pelo estabelecimento de vinculo de confiança entre elas e a enfermeira.
\end{abstract}

UNITERMOS: Enfermagem obstétrica. Cuidado pré-natal. Gestante.

\begin{abstract}
This paper reports a qualitative study conducted in an anthropological perspective using the ethnografic research methodology. It had has the objective of knowing and understanding the needs, antenatal care values and beliefs of pregnant women in the context of Prenatal Service of a Philanthropic Institution. The central theme "be treated as a Human Being", identified from the analysis of the cultural themes, revealed that, in the women experience, the most significant element is represented either by the effective interaction or by the establishment on bond of trust between them and nurse.
\end{abstract}

UNITERMS : Obstetrical nursing. Antenatal care. Pregnancy.

\section{MOTIVAÇÕES PARA O ESTUDO E OBJETIVO}

Este estudo foi motivado pela minha vivência profissional, atendendo, inicialmente, parturientes e, posterior e ultimamente, gestantes.

A minha experiência na assistência às gestantes bem como no ensino da graduação e da especialização em enfermagem obstétrica, no Serviço de Pré-Natal do Amparo Maternal, despertou minha atenção para algumas questões. Inquietava-me as condições ambientais e materiais; a alta demanda de gestantes nesse Serviço, somada à percepção, que eu tinha, da satisfação dlas gestantes quanto ao atendimento que recebiam ali, contrapondo-se às referências, sempre negativas, da assistência nas unidades básicas de saúde. A reflexão sobre essas questões levou à proposição da realização desta investigação, com o objetivo de conhecer e compreender as necessidades, crenças e valores do cuidado pré-natal, na visão e experiência vivenciada por mulheres grávidas atendidas no contexto do Serviço de Pré-Natal do Amparo Maternal, onde a assistência à gestante de baixo risco é de responsabilidade de enfermeiras-docentes.

\footnotetext{
* Resumo da Tese de Doutoramento apresentada ao Programa Interunidades de Pós-Graduação da EEUSP/EERP.USP, 1996.

** Enfermeira Obstétrica. Professor Doutor do Departamento de Enfermagem Materno-Infantil e Psiquiátrica da EEUSP.
} 


\section{TRAJETÓRIA METODOLÓGICA}

Em decorrência do objetivo proposto referirse à assistência pré-natal, os pressupostos teóricos estão relacionados com a assistência à mulher no período da gravidez, e explicita a minha concepção de que a assistência à pessoa, durante o período prénatal, deve abranger os âmbitos biológico, emocional e sócio-cultural. E, também, quando a assistência pré-natal proporciona, além do controle biologico, continente ou chão seguro para a mulher e sua família, constituindo-se, assim, em fator de coesão social, viabiliza o cuidado de enfermagem humanizado e integral, podendo, então, tornar-se um eficiente fator de redução da morbimortalidade materna e perinatal.

Tomada a decisão pela realização do estudo da assistência pré-natal, a partir da visão e experiência da mulher que a vivencia, o caminho que se mostrou adequado foi o da pesquisa qualitativa, tendo a etnografia como referencial metodológico e a antropologia cultural como referencial teórico.

A etnografia, como referencial metodológico, foi o caminho escolhido por ser um método que permite descrever um grupo cultural ou um fenômeno associado a um grupo cultural, por envolver estudo sistemático do mundo sob a ótica do indivíduo, e por ser um processo sistemático de observar, detalhar, descrever, documentar e analisar o estilo de vida de uma cultura (SPRADLEY,1979; HELMAN, 1994; LEININGER, 1985). O Amparo Maternal e as gestantes do Pré-Natal dessa Instituição podem ser considerados como um grupo cultural ou uma sub-cultura.

A antropologia cultural foi adotada como referencial teórico, por permitir a compreensão dos padrões culturais relacionados com a saúde e a doença, por orientar a pesquisa para o sistema de valores do cliente, do cuidado num contexto multifocal e da enfermagem como subcultura, e porque tem, em comum com a enfermagem, a preocupação de compreender o comportamento humano holisticamente (DOUGHERTY; TRIPP. REIMER, 1990).

A etnografia é um método de pesquisa em que a coleta de dados e a análise são simultâneas, e utiliza, para a coleta de dados, a observação participante, a entrevista e, neste estudo, também, a análise documental.

O caminho percorrido, seguindo as diretrizes metodológicas da etnografia, levou a uma compreensão do fenômeno estudado. Neste caso, a caminhada teve início com a descrição da assistência pré-natal que, à medida em que foi sendo realizada, mostrou a necessidade da descrição do cenário cultural focalizado e, também, do cenário cultural como um todo, pois o seu contexto mostrou-se necessário para a compreensão. Portanto, o caminho percorrido permitiu a descrição da assistência prénatal, do cenário cultural e do cenário cultural focalizado.

A descrição da assistência pré-natal deu-se por meio da observação participante e da realização de entrevistas com 10 informantes. As informantes foram selecionadas dentre a clientela de mulheres grávidas acompanhadas pelas enfermeiras-docentes e alunos de graduação e especialização em enfermagem obstétrica da Escola de Enfermagem da USP (EEUSP). A escolha das 8 primeiras informantes foi feita com o auxílio das colegas docentes que estavam prestando atendimento às gestantes, nos dias em que eu estava disponível para a realização das entrevistas. Esta escolha seguiu alguns critérios, entre eles o de que a gestante tivesse sido atendida, no mínimo, em 4 consultas no Serviço e demonstrasse facilidade de expressão. As duas últimas informantes escolhidas chamaram minha atenção por ocasião do atendimento prestado a elas, tanto por mim mesma como por alunos sob minha supervisão. As entrevistas foram realizadas após a consulta, nas dependências do próprio Serviço. Cada informante participou de uma a três entrevistas, sendo que, com uma delas, uma das entrevistas aconteceu após o parto, em sua casa.

As entrevistas tiveram, como questão norteadora, o significado da assistência pré-natal de um modo geral. Foram transcritas e preliminarmente analisadas, com o objetivo de verificar a necessidade de retorno à mesma informante, para esclarecimento ou aprofundamento de algum ponto que não estivesse suficientemente claro. O conteúdo das entrevistas foi analisado seguindo-se as proposições de SPRADLEY(1979) e TAYLOR; BOGDAN (1984). SPRADLEY (1979) propõe o eśtudo sistemático dos dados para a determinação das partes de uma cultura, a relação entre essas partes e a relação das partes com o todo. Isso é operacionalizado através da análise de domínio cultural. A análise dos domínios inicia-se a partir dos questionamentos feitos aos informantes e das anotações gerais obtidas das observações. Um domínio representa uma categoria simbolica do significado cultural e inclui categorias menores. Uma categoria é uma classificação de objetos diferentes, que são considerados como se fossem equivalentes. A categoria de significado cultural é um tipo de situação ou evento de uma cultura que contém categorias menores (SPRADLEY, 1979; GUALDA, 1993).

A estrutura do domínio cultural é constituída de três elementos básicos: termos incluidos ou categorias menores, termos cobertos ou nome para o domínio, relação semântica entre os termos 
incluídos e cobertos. As relações semânticas operam pelo princípio geral de inclusão, sendo sua função, definir termos incluídos e situá-los dentro de um domínio cultural (GUALDA, 1993;SPRADLEY, 1979).

Para a análise das falas das informantes, cada entrevista foi lida e relida, cuidadosamente, e foram sendo sublinhados os aspectos relativos ao objetivo do estudo. Os trechos sublinhados foram reescritos de forma a possibilitar a separação e categorização dos mesmos, levando a descoberta dos domínios culturais. A análise dos domínios culturais revelou os temas culturais, que, culminaram na descrição e compreensão do cuidado pré-natal, na perspectiva das mulheres grávidas atendidas no Serviço de PréNatal do Amparo Maternal.

Segundo SPRADLEY (1980), os temas culturais, geralmente, têm a forma de asserções e são conceituações que ligam os domínios, dando uma visão global da cultura estudada.

Para tornar claro os passos realizados para a descoberta dos domínios culturais, apresento um exemplo: dos trechos sublinhados e reescritos alguns mencionavam a presença de dor com características e localizações diversas; e referiam-se a comer muito ou a comer como "louca"; outros foram referentes a apresentar vômito, nas diversas fases da gravidez ou, ainda, mencionavam cansaço e falta de ar para a execução das atividades diárias, o que tornou possível chegar-se aos termos inclusos: dor, cansaço, alteração do apetite, falta de ar e vômito. Identificados esses termos inclusos, descobriu-se a relação semântica que os unia -é um tipo de - revelando o termo coberto - sensaçóes da gravidez, culminando, assim, na descoberta do domínio cultural denominado de tipos de sensações experimentadas pelas mulheres durante a gravidez. Esses passos foram seguidos para a identificação de todos os domínios culturais.

A descrição do cenário cultural, e do cenário cultural focalizado, foi realizada pela observação participante, por meio de informações obtidas em documentos fornecidos pela Diretora Executiva do Amparo Maternal (análise documental), através da literatura brasileira de enfermagem mas, principalmente, por depoimentos de enfermeiras, de docentes e de alunas que atuaram ou atuam no contexto, bem como de assistente social, de voluntárias da Instituição e de mulheres que foram acolhidas pelo Amparo no final da década de 50, quando se encontravam grávidas e que com esse apoio puderam reorganizar suas vidas, denominadas de "mãezinhas", pelas demais depoentes.

A investigação iniciou-se pela descrição da assistência pré-natal. A apresentação dos resultados, no entanto, segue a seguinte ordem: descrição do cenário cultural, do cenário cultural focalizado e, finalmente, a descrição da assistência pré-natal.

\section{O CENÁRIO CULTURAL - AMPARO MATERNAL}

A leitura dos documentos fornecidos pela Diretoria da Instituição revelou que por iniciativa de um grupo de pessoas, liderado por uma enfermeira da Congregação das Franciscanas Misssionárias de Maria - Madre Marie Domineuc - e pelo Professor Álvaro Guimarães Filho da Escola Paulista de Medicina, que perceberam o problema de mulheres que, após darem à luz na Clínica Obstétrica do Hospital São Paulo, não tinham para onde retornar com seus filhos, pois viviam nas ruas da cidade, fundaram o Amparo Maternal, em 20 de agosto de 1939, sob a presidência do então Cardeal Arcebispo de São Paulo D. José de Afonseca e Silva. Inicialmente, funcionou dentro do proprio Hospital São Paulo, passando para casas alugadas nas ruas próximas. Posteriormente, a Prefeitura de São Paulo, mediante o número de pessoas atendidas, julgou necessário e importante essa atividade e iniciou a construção do prédio da Rua Loefgreen, até hoje sede do Amparo Maternal. No início, as suas atividades centraram-se na área social e em 1964 entrou em funcionamento, oficialmente, o Pronto Socorro Obstétrico.

Desde a sua fundação a Instituição mantém o polêmico lema de "não recusar ninguém" que dela necessite. Tem como objetivos a assistência integral, obstétrica e social à mulher em qualquer fase do ciclo gravídico e puerperal com a finalidade de amparar a família, contribuindo para o seu reajustamento e estabilidade, estudando seus problemas com dedicação e respeito à pessoa.

Na literatura brasileira de enfermagem existem poucas referências sobre o Amparo Maternal. A mais abrangente delas foi publicada em 1968 e escrita por docentes da EEUSP (BRITEZ; TREVISI; TAJIKI, 1968). As autoras detalham a estrutura e funcionamento do Amparo e enfatizam a importância desta Instituição como campo de ensino na formação de enfermeiras obstetras e de médicos. O Amparo é mencionado, também, por AUGUSTO; MARANHÃO (1989), em resenha histórica do Departamento de Enfermagem da Escola Paulista de Medicina (EPM). Ë citado, ainda, nas publicações que fazem menção a Madre Domineuc.

Em conseqüência das modificações na legislação de ensino de enfermagem e de obstetrícia, no início da década de 70, a EEUSP passou a ser responsável pela formação da enfermeira obstétrica, gerando a necessidade de novos locais para a realização do ensino teórico-prático. Uniram-se, então, a Professora Heloisa Aparecida Leite Martins da disciplina Enfermagem Obstétrica da EEEUSP, a Madre Domineuc e o Professor Guimarães, para a 
organização do Pronto Socorro Obstétrico. Portanto, a Maternidade do Amparo nasceu do trabalho conjunto das duas instituições (Amparo e EEUSP), para solucionar problemas de ambas, pois na época o Amparo Maternal estava com dificuldade na obtenção de atendimento ao parto, para as mulheres acolhidas por ele.

Atualmente, o Amparo Maternal está sob a presidência da Cúria Metropolitana de São Paulo, representada pelo Cardeal D. Paulo Evaristo Arns e tem a direção executiva de religiosa da Congregação Vicentina. Hoje, o Amparo mantém um convênio com a EPM, atual UNIFESP (Universidade Federal de São Paulo), sendo sua Diretoria Clínica exercida por um Professor da Disciplina de Obstetrícia dessa Escola.

A História resgatada pelo depoimento das "mãezinhas", enfermeiras, docentes, alunas, assistente social e voluntárias, revelou a Madre Domineuc como a personagem central do Cenário Cultural - Amparo Maternal. As alunas destacaram a importância de vivenciar uma realidade social desconhecida para elas e a forma de atuação das docentes, como importante fator na formação profissional do enfermeiro.

\section{O CENÁRIO CULTURAL FOCALIZADO - O PRÉ-NATAL}

O Pré-Natal, como cenário cultural focalizado, teve sua história resgatada pelos relatos das enfermeiras, docentes e alunas, mostrando a existência da assistência pré-natal no Amparo Maternal desde o início de suas atividades, mesmo antes do funcionamento da Maternidade, revelando a importância dada a essa assistência por seus fundadores, principalmente pela Madre Domineuc. Inicialmente, contava apenas com uma sala com banheiro e um arquivo. Foram destacadas, no depoimento das enfermeiras, a alta demanda de clientes e as dificuldades de entrosamento com a equipe médica, posteriormente à saída do Professor Guimarães da direção da Instituição. O atual Serviço de Pré-Natal é descrito através da fala das docentes de enfermagem responsáveis pelo ensino nesta unidade, as quais destacaram a qualidade da assistência prestada, a diversificação da clientela, que inclui tanto mulheres socialmente excluídas como de melhor nível educacional e econômico, e a problemática da grande demanda de clientela. Este Serviço foi, unanimemente, destacado enquanto campo de ensino teórico-prático, pois oferece diversidade de oportunidades.

$\mathrm{O}$ ambulatório, onde funciona o Serviço de Pré. Natal, situa-se num piso inferior à entrada do
Hospital. Após passar pela portaria, é necessário percorrer uma distância entre 100 e $200 \mathrm{~m}$ pelo estacionamento. No final deste trecho, existe uma lanchonete, ao lado da qual inicia-se uma rampa, cimentada, que dá acesso à entrada do Ambulatório onde, além do Pré-Natal, funciona o Serviço de Ultrassonografia.

Para o atendimento as gestantes existem 6 consultórios, 3 para cada uma das Escolas de Enfermagem que lá atuam. Cada consultório dispõe de divã ou mesa para o exame físico e obstétrico, escrivaninha, cadeiras e pia com torneira. Todos os consultórios possuem janelas grandes, de vidro branco fosco, permitindo arejamento do ambiente, contrariamente à sala de espera que, além de pouco arejada, é pequena para comportar o número de mulheres atendidas por período.

O Serviço de Pré-Natal funciona de segundafeira à sexta-feira, nos dois períodos, manhã e tarde. No período da manhã, as enfermeiras-docentes das Escolas de Enfermagem da USP e UNIFESP atendem as gestantes de baixo risco gestacional. As gestantes de médio e alto risco são atendidas pelos médicos residentes da Escola Paulista de Medicina, da UNIFESP, no período da tarde.

Para o atendimento do período da manhã, as gestantes são orientadas a chegar às 7 horas, para entregar o cartão de pré-natal, sendo atendidas pela ordem de chegada, entre $7 \mathrm{~h} 30 \mathrm{~m}$ e $12 \mathrm{~h}$. Cada Escola de Enfermagem organiza sua agenda diária, e transfere o atendimento da gestante para o período da tarde, quando detectam patologias associadas, que implicam em risco gravídico.

\section{DESCRIÇÃO DA ASSISTÊNCIA PRÉ-NATAL}

A descrição da Assistência Pré-Natal compõese da apresentação das mulheres, ou seja, das gestantes que são as informantes do estudo, e da descrição dos domínios culturais. As mulheres são apresentadlas com nomes fictícios, para manter o anonimato e com algumas de suas particularidades, principalmente as relacionadas com a historia obstétrica.

Os domínios culturais descobertos seguindo. se as proposições de SPRADLEY (1979) e TAYLOR; BOGDAN(1984) foram os seguintes: a vivência do tornar-se grávida; os sentimentos vivenciados pelas mulheres durante a gravidez; o medo vivenciado pelas mulheres durante a gravidez; as sensações experimentadas pelas mulheres durante a gravidez; razões das mulheres para buscarem e freqüentarem serviços de pré-natal; o pré-natal; dificuldades enfrentadas pelas mulheres para o atendimento pré-natal; razões para as mulheres definirem 
preferência por local para a assistência no periodo da gravidez; razões para as mulheres avaliarem o atendimento no Amparo Maternal; sentimentos vivenciados pelas mulheres em decorrência da assistência pré-natal recebida no Amparo Maternal.

\section{COMPREENDENDO O CUIDADO PRÉ- NATAL}

A descrição e análise dos dez domínios culturais identificados, do cenário cultural e do cenário cultural focalizado, permitiram a identificação de três Temas Culturais: "Toda mãe que é mãe mesmo quer saber o que está acontecendo com o seu filho"; Convivendo com o dilema entre quantidade e qualidade; "PréNatal é melhor onde conversam e explicam as coisas pra gente". Isso levou à compreensão das necessidades, crenças e valores do cuidado pré-natal na visão e experiência das mulheres/informantes do Amparo, revelando o tema central "ser tratada como gente".

Na crença das mulheres, a gravidez mostrouse dependente de dois fatores: do proprio desejo e de licença divina. Quando a gravidez foi indesejada ou não planejada, levou as mulheres a vivenciá-la com sentimentos como o da solidão e o do desespero. Quando a gravidez foi desejada ou desejada e planejada, o sentimento que predominou foi o de felicidade, sendo este sentimento considerado como aquele que representa o que é ser mãe. No entanto, em ambos os casos, houve a predominância de sentimentos negativos, representados pela clúvida e pelo medo. Inicialmente, medo de não ser fértil, e ser fértil é necessário para atender a um padrão cultural da comunidade onde vivem. Em seguida, quando notam a ausência da menstruação, pensam que estão com alguma doença e, nunca, que possam estar grávidas. Superada essa dúvida quanto a doença ou gravidez, que se faz mediante o uso de tecnologia, como a ultrassonografia, o medo é causado pela preocupação com a higidez e bem-estar fetal, em função da responsabilidade que sentem sobre essa nova vida em desenvolvimento dentro de si mesmas.

No entanto, por desconhecimento e inabilidade quanto à percepção corporal, elas não conseguem sinais concretos da existência e do bem-estar fetal, o que não lhes permite uma referencia de normalidade do feto. Esses fatos, somados ao conhecimento de que a própria higidez está relacionada com o bem-estar fetal, certeza esta que não conseguem obter sozinhas, resulta na predominância de sentimentos negativos, principalmente o medo, tornando a busca por cuidado profissional durante a gravidez, uma questão imperativa para elas. Isto porque, para essas mulheres, "toda mae que é mae mesmo quer saber o que está acontecendo com o seu filho".

A necessidade das mulheres grávidas de saberem o que está acontecendo com o seu filho faz com que enfrentem uma série de obstáculos, com a finalidade de cumprir o que, para elas, acaba sendo uma obrigação natural da mulher grávida, o acompanhamento do desenvolvimento do bebê e de seu próprio estado de saúde, através do cuidado profissional. Algumas delas, simplesmente, sentem essa necessidade apesar de, às vezes, não compreenderem o porquê. É importante destacar que as mulheres reconhecem o pré-natal como cuidado preventivo de saúde, sendo este o único momento em que a mulher procura cuidado profissional, mesmo não apresentando qualquer sintoma. Os obstáculos enfrentados pelas mulheres estão ligados à estrutura e funcionamento do sistema de saúde e, também, às características pessoais do profissional. Dessa forma, comprovou-se a dificuldade de acesso das mulheres à rede pública de saúde e, conseqüentemente, o não cumprimento dos objetivos do Programa de Atenção Integral à Saúde da Mulher (PAISM) (SÃO PAULO, 1986), revelando que a peregrinação das mulheres inicia-se desde a gravidez e, portanto, antes da já conhecida e discutida peregrinação das mulheres grávidas para a assistência ao parto. Finalmente, quando elas conseguem atendimento em serviço de pré-natal, deparam-se com o despreparo e descompromisso dos profissionais, que não lhes dão atenção, estão sempre apressados e, portanto, não conseguem estabelecer interação com as mulheres que, assim, julgam o atendimento apressado e sem profundidade, comprometendo, desta forma, a efetividade da assistência pré-natal. Algumas delas, não satisfeitas, peregrinam novamente em busca da satisfação de suas necessidades. Outras, desestimulam-se e, em gravidez subseqüente, não mais freqüentam serviços de pré-natal ou o fazem tardiamente, apenas na tentativa de garantir vaga para o parto.

O tema cultural "Convivendo com o dilema entre quantidade e qualidade" surge da compreensão do contexto cultural onde a assistência pré-natal está sendo descrita. No resgate histórico o Amparo Maternal revelou-se como uma Instituição fortemente estigmatizada, por acolher mulheres solteiras grávidas, estar com suas portas sempre abertas e pelo comportamento machista e moralista da sociedade. As mulheres acolhidas pelo Amparo enfrentavam uma série de dificuldades, pelo estigma da Instituição e pela deficiência de recursos materiais e humanos. Pela fala das "mãezinhas" $\mathrm{e}$ das alunas, percebe-se que tais dificuldades eram superadas pela competência, dedicação e 
envolvimento dos profissionais, respeitando os dogmas da igreja católica como eixo norteador da assistência ali prestada, fazendo as mulheres perceberem que eram respeitadas como seres humanos e sentirem-se, novamente, pertencentes a uma família. As mulheres viam na Madre e no Professor Guimarães os pais que perderam ou nunca tiveram.

Assim, as dificuldades eram superadas e transformadas ou vividas com sentimento de felicidade e amor, que, juntamente com o apoio material recebido, tornou possível a formação de novos núcleos familiares. Núcleo familiar representado, às vezes, pelo binômio mãe-filho, defendido pela Madre, conceito este, incompreendido na época.

A Madre Domineuc considerava que a mulher abandonada em estado gravídico, em conseqüência da agressividade sofrida no meio social e da solidão, vivenciava muito sofrimento, sofrimento este para o qual a Madre via na atuação da enfermeira uma possibilidade de apoio seguro, transformando o sofrimento, pela compreensão, em confiança, levando a mulher a vivenciar o trabalho de parto com serenidade eutócica. A Madre publicou artigo na Revista Brasileira de Enfermagem, em 1957, onde destacava a influência do estado emocional da mulher na evolução do trabalho de parto (DOMINEUC, 1957).

Da fala das mulheres/informantes, organizada nos domínios culturais sobre a vivência da assistência pré-natal no Amparo Maternal, emergiu o terceiro tema cultural: "pré-natal é melhor onde conversam e explicam as coisas pra gente".

A assistência recebida no Amparo mostrou-se efetiva, na medida em que proporcionou a transformação da vivência de sentimentos negativos. Essa transformação deve-se ao conhecimento adquirido através da vivência da própria experiência, que sendo positiva supera o imaginário da mulher, fortemente influenciado pelo conhecimento cultural, aprendido em seu meio social e através da mídia. A vivência positiva da experiência é resultado do conhecimento do processo gravídico e do bem-estar fetal, obtido pelo fato de ter havido interação efetiva ou o estabelecimento de vínculo de confiança entre a mulher, o aluno e a enfermeira. Este fato, acrescido da percepção das mulheres quanto à competência, e a dedicação das enfermeiras-docentes e alunos e por sentirem-se consideradas como gente, melhora a auto-estima e confiança em si mesmas, levando-as a sentirem que pisam em chão seguro, o que é necessário em época de transição existencial.

Desse modo, a assistência pré-natal de enfermagem gera sentimentos de confiança, de segurança e crescimento emocional, fazendo com que as mulheres tenham uma avaliação positiva do atendimento recebido no Amparo Maternal. Por isso, elas consideram que "o pré-natal é melhor onde conversam e explicam as coisas pra gente".

No entanto, para algumas mulheres, a assistência pré-natal do Amparo não apresentou a efetividade esperada, ou seja, não conseguiu proporcionar o chão seguro para que pudessem caminhar rumo a um crescimento emocional, resultando em avaliação negativa. Fica claro que, para essas mulheres, além do atendimento individual, há necessidade do efeito reassegurador proporcionado pelo trabalho em grupo de gestantes, com o uso de metodologia participativa.

O trabalho em grupo de gestante deve ser, efetivamente, considerado como uma atividade integrante da assistência pré-natal e não somente constar dos Programas oficiais dos órgãos públicos de saúde. Desta forma, a assistência pré-natal pode mostrar-se mais eficaz, não apenas para a redução da mortalidade materna e perinatal mas, também, como importante fator de prevenção primária de saúde emocional. Concordamos com MALDONADO (1990), em que o trabalho de grupo ajuda a conscientização das mulheres em relação ao atendimento que recebem e à reivindicação de suas necessidades. O trabalho preventivo, durante a gestação, pode ser considerado um instrumento político, pois, ao estimular a reflexão, encoraja a luta contra a passividade e a submissão. Assim, pode-se favorecer a organização e instrumentalização das mulheres para formas de luta que possuam força política e leve-as rumo à conquista da cidadania.

A interação é instrumento básico da enfermeira na assistência à mulher e à família, durante a gravidez, o parto e o puerpério. É a interação que possibilita a execução de cuidados culturalmente congruentes, contribuindo para 0 alcance do principal objetivo da assistência pré. natal, que é o de reduzir a morbimortalidade materna e perinatal. A interação é possível com a adoção, pela enfermeira, da atitude clínica. A atitude clínica é a "a capacidade de ver, ouvir e de sintonizar com a cliente a partir da perspectiva dela, e não somente da nossa". Assim, a enfermeira, conscientemente, faz uso terapêutico de si mesma (MALDONADO; CANELLA, 1988 ; STEFANELLI, 1993).

\section{SER TRATADA COMO GENTE}

O caminho percorrido para a realização deste estudo permitiu o alcance do objetivo proposto com a identificação do tema central "ser tratada como gente" e, também, possibilitou outras revelações, 
principalmente as de que os fundamentos da enfermagem obstétrica praticada e ensinada pela Madre Domineuc já na década de 50 estão, de certo modo, contidos nas Teorias Interacionistas de Enfermagem.

Dentre as autoras nacionais, destaco STEFANELLI (1993), que assim não o denomina, mas apresenta uma figura onde deixa claro que a excelência do cuidado de enfermagem baseia-se no tripé formado pela comunicação, pela enfermeira $e$ pelo paciente. A forma de atuação e de ensino da Madre Domineuc no Amparo Maternal contempla a proposta de HORTA (1976), contida no Editorial da Revista Enfermagem em Novas Dimensões, onde destaca que: “... o que nos coloca na posição de cuidar de gente é o preparo técnico-científico e a formação humanística que adquirimos nas escolas de enfermagem... Todo o preparo técnico-científico... será insuficiente para dar ao enfermeiro a verdadeira significação da enfermagem se lhe falta a formação humanística e a capacidade de ser gente que cuida de gente; nesta impossibilidade ele será coisa que cuida de coisa. Cada um de nós é responsável pelo crescimento de seu próprio ser, não somos completos nem acabados, estamos num perpétuo estado de 'vir a ser', é no contato com outros seres humanos, no compromisso que assumimos quando optamos pela profissão de enfermagem, que construimos, palmo-a-palmo o nosso ser e, simultaneamente, auxiliamos nosso semelhante na construção e crescimento do eu ".

A valorização da formação humanística, tanto quanto a da capacitação em relacionamento interpessoal, são necessários para o ensino da enfermagem e da enfermagem obstétrica na preservação da excelência do cuidado de enfermagem à mulher no período gravídico, constituindo-se, juntamente com outros fatores, em eficiente fator de redução dos índices de morbimortalidade materna e perinatal. Desta forma, realmente seremos gente cuidando de gente.

\section{REFERÊNCIAS BIBLIOGRÁFICAS}

AUGUSTO, M.; MARANHÃO, A.M.S. de A. Resenha histórica do Departamento de Enfermagem da Escola Paulista de Enfermagem. In: JUBILEU DE OURO DO CURSO DE GRADUAÇĀO EM ENFERMAGEM DA ESCOLA PAULISTA DE MEDICINA, Săo Paulo, 1989. Anais. São Paulo, Escola Paulista de Medicina, Departamento de Enfermagem, 1989. p.17-22.

BRITEZ, E.; TREVISI, D.; TAJIKI, S.T. O "Amparo Maternal" como campo de ensino para a enfermagem. Rev.Esc.Enf.USP, v.2, n.1, p.61-75, 1968.

DOMINEUC, M. A mae solteira, responsabilidade para a enfermeira. Rev. Bras. Enf., v.10, n.4, p.357-63, 1957.

DOUGHERTY, M.; TRIPP-REIMER, T. Nursing and anthropology. In: JOHNSON, T.M.; SARGENT, C.F. Medical anthropology: contemporary theory and method. New York, Praeger, 1990. cap.10, p.174-85.

GUALDA, D.M.R. Eu conheço minha natureza: um estudo etnográfico da vivência do parto. São Paulo, 1993. 288p. Tese (Doutorado) - Escola de Enfermagem, Universidade de São Paulo.

HELMA. C.G. Cultura, saúde e doença. 2.ed. Porto Alegre, Artes Médicas, 1994.

HORTA, W. de A. Gente que cuida de gente./Editorial/. Enf. Novas Dimens. , v.2, n.4, p.III, 1976.

LEININGER, M.M. Qualitative research methods in nursing. Detroit, Grune \& Stratton, 1985. cap. 3, p.33-71: Ethnographic and ethnonursing - models and modes of qualitative data analysis.

MALDONADO, M.T. Maternidade e paternidade: a assistência no consultório e no hospital. Petrópolis, Vozes, 1990. v.1.

MALDONADO, M.T.; CANELLA, P. A relação médico-cliente em ginecologia e obstetrícia. 2. ed. Såo Paulo, Roca, 1988.

SÃO PAULO (Estado). Secretaria de Estado da Saúde. Subprograma de saúde da mulher: subsídios e diretrizes. Săo Paulo, Grupo de Saúde da Mulher, 1986

SPRADLEY, J. The ethnographic interwiew. New York, Holt Rinehart \& Winston, 1979.

SPRADLEY, J. Participant-observation. New York, Holt Rinehart \& Winston, 1980

STEFANELLI, M.C. Comunicação com paciente: teoria e ensino. 2.ed. Sao Paulo, Robe, 1993.

TAYLOR, S.J.; BOGDAN, R. Introduction to qualitative research methods : the search for meanings. New york, John wiley \& Sons, 1984. 